\title{
Evidence of Specific Healthy Behaviors Positively Associated with General Life Satisfaction among Rural Adults
}

\author{
Ming-Shyan Lin', Po-Han Chen2, Wen-Nan Chiu ${ }^{3}$, Mei-Yen Chen ${ }^{4}$ \\ ${ }^{1}$ Division of Cardiology, Chang Gung Memorial Hospital, Taiwan \\ ${ }^{2}$ Department of Orthopedic Surgery, Chang Gung Memorial Hospital, Taiwan \\ ${ }^{3}$ Department of Internal Medicine, Chang Gung Memorial Hospital, Taiwan \\ ${ }^{4}$ Department of Nursing, Chang Gung University of Science and Technology, Taiwan \\ Email: mingshyan@gmail.com, chaos5408@gmail.com, wendy0625@cgmh.org.tw, \\ "meiyen@gw.cgust.edu.tw
}

Received 19 May 2016; accepted 10 June 2016; published 13 June 2016

Copyright (C) 2016 by authors and Scientific Research Publishing Inc.

This work is licensed under the Creative Commons Attribution International License (CC BY). http://creativecommons.org/licenses/by/4.0/

(c) (i) Open Access

\section{Abstract}

Background: Chronic diseases are the leading causes of death worldwide. Evidence suggests that infrequent adopting healthy behaviors correlated with many chronic diseases. Healthy behaviors can lead to a marked reduction of morbidity and mortality. Life satisfaction is an important parameter of well-being. Few studies have focused on the association between healthy behaviors and life satisfaction among adults in rural areas. Aim: To establish the determinant and modifiable lifestyle factors associated with life satisfaction among rural adults. Methods: We analyzed our previous health promotion program in a rural area in 2013 obtained from 27 villages $(n=8024)$ in Yunlin County, Taiwan. The assessment comprised one question assessing self-reported life satisfaction on a 5-point scale (dichotomous: low satisfaction/high satisfaction) and four domainspecific items of health-related behaviors (smoking, oral hygiene, exercise, healthy diet). Logistic regression was used to examine the association between health-related behaviors and life satisfaction adjusted for age, sex, and education. Findings: The mean age was 47.6 years $(S D=16.2)$, and $56.7 \%(n=4551)$ of the participants were female. Participants with lower life satisfaction reported frequently perceived dissatisfaction with sleep quality $(p<0.001)$ and health status $(p<$ 0.001). After adjusting for potential confounding variables, the associated risk factors for lower life satisfaction were smoking $(O R=1.20, p=0.006)$, less frequently adopted healthy behaviors including dental check $(O R=1.23, p<0.001)$, infrequent teeth brushing $(O R=1.12, p=0.022)$, infrequent use of dental floss ( $O R=1.12, p=0.028)$, infrequent consumption of a balanced diet (OR $=1.64, p<0.001)$, insufficient vegetable intake $(O R=1.19, p=0.001)$, insufficient water intake $(O R=1.14, p=0.009)$, and infrequent regular exercise $(O R=1.26, p<0.001)$. Conclusions: The ${ }^{*}$ Corresponding author.

How to cite this paper: Lin, M.-S., Chen, P.-H., Chiu, W.-N. and Chen, M.-Y. (2016) Evidence of Specific Healthy Behaviors Positively Associated with General Life Satisfaction among Rural Adults. Open Journal of Preventive Medicine, 6, $161-169$. http://dx.doi.org/10.4236/ojpm.2016.66015 
findings showed that many adults did not adopt healthy habits in their life. This study identified significant unhealthy behaviors associated with lower life satisfaction, including cigarette smoking, unhealthy diet, poor oral hygiene, and physical inactivity. The enhancement of health promotion programs to improve life satisfaction through decreasing unhealthy habits is necessary for rural adults.

\title{
Keywords
}

\author{
Life Satisfaction, Healthy Behaviors, Adults, Rural Areas
}

\section{Introduction}

Chronic diseases are the leading causes of death and disability worldwide. Many studies indicate that unhealthy behavior is associated with chronic diseases, such as cardiovascular disease, stroke, diabetes, and cancer [1]. With the increasing burden of chronic diseases in Taiwan, the National Health Insurance is facing financial shortages with the $99.6 \%$ coverage of the Taiwanese population. Debates and discussions about increasing co-pay among politicians occur more often and induce instability in the infrastructure of the health sector of government [2]. According to the literature, healthy behaviors can lead to a marked reduction of morbidity and mortality and are positively correlated with health status [2]-[4]. An important role for clinicians and primary health care providers is to initiate healthy behavior programs in their work settings. Many studies indicate that healthy behaviors include no smoking, a healthy diet (5 groups of a balanced diet, sufficient vegetables, fruit, and fluids in the form of water), good oral hygiene (tooth brushing, using dental floss, regular dental check, and biannual cleaning), and regular exercise [1] [4]-[6]. In addition, numerous studies support the protective effect of consuming 2 portions of fruit and vegetables (at least 3 portions) to prevent chronic disease, cancer, and cardiovascular disease [2] [7] [8].

In the last two decades, the concept of Quality of Life (QoL) has been commonly used in medicine and health care for measuring a patient's subjective view of overall well-being and as an outcome measure in clinical, community, or research settings [9] [10]. The World Health Organization has defined QoL as individuals' perception of their position in life in the context of the culture and value systems in which they live and in relation to their goals, expectations, standards, and concerns [11]. In addition, the concept of QoL has been popularly adopted as a complementary perspective to the more traditional disease-specific perspective. Many studies used the health-related Short Form-36 (SF-36) questionnaire for QoL assessment, which is a multidimensional construct covering physical, emotional, mental, social, and behavioral components of well-being and functioning as subjectively perceived by a person depending on the cultural context and value system [12].

Until now, QoL has been commonly used by many studies in different cultures to measure the relationships between QoL and specific health issues, such as obesity in children and adults [13], chronic illnesses, including hypertension, chronic obstructive pulmonary disease, and cardiovascular disease [9] [14] [15], elderly populations and postmenopausal women [16] [17], physical disability [18], and informal carers [19]. QoL has been found correlated with life satisfaction, sleep quality, and general health status [20]. In Taiwan, a short form of the HRQoL with 28 items using a 5-point Likert scale has been a popular instrument for measuring QoL and general life satisfaction, happiness, and general perception of health status [21]. However, in a rural community setting, it is unrealistic to measure QoL using such a comprehensive tool with five domains for a health screening.

According to a study of 1289 patients with cardiovascular disease in Luxembourg, Baumann et al. [9] used a general approach of one item of life satisfaction (response range 1 - 10, 10 indicating the highest score of life satisfaction), and found that subjects with physical inactivity, obesity, diabetes, or hypercholesterolemia were more likely to have a lower life satisfaction. Considering the feasibility and response rate, we therefore opted for a general approach of one item to measure life satisfaction. Additionally, few studies have focused on healthrelated behaviors associated with life satisfaction. Therefore, the aim of this study was to explore the determinant factors and relationship between unhealthy behaviors, contextual factors, and general life satisfaction among adults in a rural area. 


\section{Materials and Methods}

\subsection{Study Design and Population}

This study was part of a community-based health screening survey that was conducted in a disadvantaged area in collaboration with a local hospital in Yunlin County, Taiwan, in 2013. The inclusion criteria were 1) age over 20 years, 2) complete independence in managing daily life, 3) ability to complete the questionnaires in Mandarin or Taiwanese dialects either by self-administration or interview, 4) ability to walk to the local corporate hospital, and 5) provision of signed informed consent before enrollment in the study. Exclusion criteria were 1) mental health problems, including a disability certificate or a diagnosis of dementia; 2) severe chronic disease (e.g., involving dialysis), cancer, or inadequately controlled diabetes; and 3) inability to walk to the local hospital for physical examination.

\subsection{Measurements}

This study consisted of five items in one brief questionnaire, including demographic characteristics (age, sex, and educational attainment), life satisfaction, health-related behaviors, self-perceived sleep quality, and selfperceived health status.

1) Life satisfaction was measured by one general question: "In general, how do you rate your life satisfaction?" that was based on the literature and easy to use routinely [9]. Each participant self-rated the degree of their level of satisfaction with life on a scale from 1 to 5 , with 5 being the highest rating. The answers were categorized, with scores of 1 - 3 indicating Low Life Satisfaction (LLS), and scores of 4 - 5 indicating high life satisfaction (HLS).

2) Health-related behaviors were measured by four main questions: 1) "Do you smoke cigarettes?” Participants were classified as "never" if they never smoked, "cessation" if they had smoked but stopped for half year, or "current user" if they were currently smoking. 2) Oral hygiene was assessed using three questions: a) "Do you regularly visit a dental clinic for dental check and cleaning each year?" The answers were categorized as "frequent" ( $\geq$ once a year) or "less frequent" (never/seldom). b) "How often do you brush your teeth after a meal each day?" The answers were categorized as "frequent" ( $\geq$ twice a day) or "less frequent" $(\leq 1)$. c) "How often do you use dental floss after a meal each day?" The answers were categorized as "frequent" ( $\geq$ once a day) or "less frequent" (never/seldom). 3) Healthy diet was assessed using four questions: a) "How often do you have a balanced diet with 5 nutritional groups per day?” b) "Do you have 3 portions of vegetables every day?” c) "Do you have 2 portions of fruit every day?” d) "How often do you drink $1500 \mathrm{~mL}$ of water each day?” The answers of these diet-related items were classified as "less frequent" if participants answered never or sometimes, and as "frequent" if their answer was usually or always. 4) Regular exercise was assessed with one question: "How often do you exercise each day?" The responses were classified as "less frequent" if the answer was never or sometimes and "frequent" if participants usually exercised for a total or cumulative time of $>30$ min per day, three times per week, or 150 min per week.

3) Self-perceived sleep quality was measured by one general question: "In general, how do you rate your sleep quality?” The answers were categorized as "unsatisfied," "fair/average,” and "satisfied.”

4) Self-perceived health status was measured by one general question: "In general, are you satisfied with your health?” The answers were categorized as "unsatisfied,” "fair/average," and "satisfied."

\subsection{Procedure and Ethical Considerations}

This study was approved by the Ethical Committee of the Institutional Review Board (Chang Gung Memorial Hospital IRB-1024399B). Written informed consent was obtained from all participants. A cover letter, which asked for participation in the study, was sent either by the research assistants or village leaders and emphasized that the responses would be confidential. The researcher notified each participant that a free medical evaluation would be conducted. All participants were interviewed face-to-face or self-administered the questionnaire after the physical check-up at the collaborating hospital. The research assistants were trained for 4 hours by the investigators. The Content Validity Index (CVI) of the instrument was judged by a panel of 5 experts in health promotion and health education and by physicians $(\mathrm{CVI}=0.92)$. Some items within the instruments were revised according to the experts' suggestions. The inter-rater reliability achieved 90\% correspondence of responses among the 10 research assistants who were all senior nursing students. 


\subsection{Data Analysis}

Categorical variables were presented as numbers and percentages and continuous variables were displayed as means and standard deviations. The distribution of the demographical variables for LLS and HLS was analyzed using chi-square test for categorical variables and independent sample t-test for continuous variables. To investigate the associated factors of life satisfaction, a multivariable logistic regression analysis was conducted. The results are presented as adjusted odds ratio (OR) with the corresponding 95\% confidence interval (CI). All data analyses were conducted using SPSS 22 (IBM SPSS Inc).

\section{Results}

\subsection{Demographic Characteristics and Health-Related Habits}

Among the 9041 residents who participated in this community health survey, 8024 met the inclusion criteria and completed the questionnaire. There were 3473 (43.3\%) male and 4551 (56.7\%) female subjects with a mean age of 47.6 years $(S D=16.2)$. Exactly half of the subjects $(N=4012)$ were classified as having LLS, while the other half reported HLS. Table 1 shows that more than two thirds of participants $(N=5683)$ received less than a senior high school education and 20.5\% $(N=1643)$ were current smokers. Regarding oral health, infrequent dental check-up ( $N=5725,71 \%)$, tooth brushing $(N=5210,65 \%)$, and use of dental floss $(N=5075,63 \%)$ were reported. An insufficiently healthy diet was found in $21 \%(N=1693)$, sufficient vegetable intake was reported by $34 \%(N=2752)$, fruit intake by $56 \%(N=4500)$, and water intake by $38 \%(N=3059)$. In addition, $70 \%(N=$ $5641)$ reported infrequent regular exercise. Nearly one quarter $(23 \%, N=1855)$ reported dissatisfaction with their sleep quality, and 13\% $(N=1073)$ were unsatisfied with their health status.

Table 1. Demographic characteristics and specific healthy behaviors associated with life satisfaction $(N=8024)$.

\begin{tabular}{|c|c|c|c|}
\hline Variable & $\begin{array}{c}\text { LLS }^{*} \\
(\mathrm{~N}=4012)\end{array}$ & $\begin{array}{c}\text { HLS }^{\ddagger} \\
(\mathrm{N}=4012)\end{array}$ & $\mathrm{p}$ value \\
\hline Age (year) & $46.3 \pm 15.9$ & $48.9 \pm 16.4$ & $<0.001$ \\
\hline Age $\geq 65$ years & $624(15.6)$ & $844(21.0)$ & $<0.001$ \\
\hline Female gender & $2273(56.7)$ & $2278(56.8)$ & 0.910 \\
\hline Secondary school or below & $2817(70.2)$ & $2866(71.4)$ & 0.229 \\
\hline Current smoker & $903(22.5)$ & $740(18.4)$ & $<0.001$ \\
\hline \multicolumn{4}{|l|}{ Oral hygiene } \\
\hline Dental check (less frequent) & 2994 (74.6) & $2731(68.1)$ & $<0.001$ \\
\hline Brushing teeth (less frequent) & $2750(68.5)$ & $2460(61.3)$ & $<0.001$ \\
\hline Using dental floss (less frequent) & $2606(65.0)$ & $2469(61.5)$ & 0.002 \\
\hline \multicolumn{4}{|l|}{ Healthy diet } \\
\hline Balance diet (less frequent) & $1076(26.8)$ & $617(15.4)$ & $<0.001$ \\
\hline Vegetable intake (less frequent) & $1584(39.5)$ & $1186(29.6)$ & $<0.001$ \\
\hline Fruit (less frequent) & $2425(60.4)$ & 2075 (51.7) & $<0.001$ \\
\hline Water (less frequent) & $1666(41.5)$ & $1393(34.7)$ & $<0.001$ \\
\hline Regular exercise (less frequent) & 2995 (74.7) & $2646(66.0)$ & $<0.001$ \\
\hline Self-reported sleep quality & & & $<0.001$ \\
\hline Unsatisfied & $1297(32.4)$ & $558(13.9)$ & \\
\hline Fair & 1939 (48.3) & $1086(27.1)$ & \\
\hline Satisfied & 776 (19.3) & $2368(59.0)$ & \\
\hline Self-perceived health status & & & $<0.001$ \\
\hline Unsatisfied & $846(21.1)$ & $227(5.7)$ & \\
\hline Fair & 2976 (74.2) & $883(22.0)$ & \\
\hline Satisfied & $190(4.7)$ & $2902(72.3)$ & \\
\hline
\end{tabular}

"LLS: Lower life satisfaction, ${ }^{+} \mathrm{HLS}$ : higher life satisfaction. 


\subsection{Factors Associated with Lower Life Satisfaction}

The results indicated that the participants with LLS tended to be younger, more likely to smoke, less frequently receiving regular dental check or cleaning $(\mathrm{p}<0.001)$, less frequently brushing teeth after a meal $(\mathrm{p}<0.001)$, less frequently using dental floss $(\mathrm{p}=0.002)$, less frequently eating a balanced diet $(\mathrm{p}<0.001)$, less frequently having sufficient vegetable intake ( $p<0.001)$, less frequently having sufficient fruit intake $(p<0.001)$, less frequently having sufficient water intake $(\mathrm{p}<0.001)$, and less likely doing regular exercise $(\mathrm{p}<0.001)$ when compared to participants with HLS (Table 1). In addition, participants with LLS also reported dissatisfaction with sleep quality $(\mathrm{p}<0.001)$ and health status $(\mathrm{p}<0.001)$. Noticeably, there was no correlation between life satisfaction and gender or education level.

Similar results were observed when the analyses were further stratified by gender. Nevertheless, female participants with LLS tended to have higher levels of education, while this correlation was not found for the male counterparts. Male participants with LLS less frequently used dental floss, while this correlation was not apparent for the female cohort (Table 2).

When incorporating the significant variables associated with life satisfaction listed in Table 1 into the multivariable logistic regression, the results suggested that a younger age ( $\mathrm{OR}=0.72,95 \% \mathrm{CI}$ : $0.63-0.82)$, cigarette smoking $(\mathrm{OR}=1.20,95 \% \mathrm{CI}: 1.05$ - 1.36), infrequent dental check (OR $=1.23,95 \% \mathrm{CI}: 1.10$ - 1.36), infrequent brushing of teeth after a meal (OR $=1.12,95 \% \mathrm{CI}: 1.02-1.23)$, infrequent use of dental floss (OR $=1.12,95 \%$ CI: 1.01 - 1.23), infrequent balanced diet ( $\mathrm{OR}=1.64,95 \% \mathrm{CI}: 1.45-1.84)$, insufficient vegetable intake $(\mathrm{OR}=$ 1.19, 95\% CI: 1.07 - 1.32), insufficient water intake (OR = 1.14, 95\% CI: $1.03-1.25)$, and infrequent regular exercise (OR $=1.26$, 95\% CI: 1.14 - 1.39) were associated with LLS. The results further suggested that gender, education level, and frequency of fruit intake were not independent factors associated with life satisfaction (Table 3).

Table 2. Specific Healthy Behaviors Associated with Life Satisfaction Stratified by Gender.

\begin{tabular}{|c|c|c|c|c|c|c|}
\hline \multirow[b]{2}{*}{ Variables } & \multicolumn{3}{|c|}{ Male $(n=3473)$} & \multicolumn{3}{|c|}{ Female $(n=4551)$} \\
\hline & $\begin{array}{c}\text { LLS }^{*} \\
(\mathrm{~N}=1739)\end{array}$ & $\begin{array}{c}\text { HLS } \\
(\mathrm{N}=1734)\end{array}$ & $P$ & $\begin{array}{c}\text { LLS } \\
(\mathrm{N}=2273)\end{array}$ & $\begin{array}{c}\text { HLS } \\
(\mathrm{N}=2278)\end{array}$ & $\mathrm{p}$ \\
\hline Age, year & $46.5 \pm 16.0$ & $48.3 \pm 16.1$ & $<0.001$ & $46.2 \pm 15.9$ & $49.4 \pm 16.6$ & $<0.001$ \\
\hline Age $\geq 65$ years & $285(16.4)$ & 344 (19.8) & 0.008 & 339 (14.9) & 500 (21.9) & $<0.001$ \\
\hline Secondary school or below & $1211(69.6)$ & $1194(68.9)$ & 0.619 & $1606(70.7)$ & $1672(73.4)$ & 0.039 \\
\hline Current smoker & $766(44.0)$ & 667 (38.5) & $<0.001$ & $137(6.0)$ & $73(3.2)$ & $<0.001$ \\
\hline \multicolumn{7}{|l|}{ Oral hygiene } \\
\hline Dental check/scaling (in frequent) & $1351(77.7)$ & $1196(69.0)$ & $<0.001$ & $1643(72.3)$ & $1535(67.4)$ & $<0.001$ \\
\hline Brushing teeth (infrequent) & $1245(71.6)$ & $1106(63.8)$ & $<0.001$ & $1505(66.2)$ & $1354(59.4)$ & $<0.001$ \\
\hline Dental floss (infrequent) & $1185(68.1)$ & $1096(63.2)$ & 0.002 & $1421(62.5)$ & $1373(60.3)$ & 0.120 \\
\hline \multicolumn{7}{|l|}{ Healthy diet } \\
\hline Balance diet (infrequent) & $490(28.2)$ & 285 (16.4) & $<0.001$ & $586(25.8)$ & $332(14.6)$ & $<0.001$ \\
\hline Vegetable (infrequent) & $802(46.1)$ & $608(35.1)$ & $<0.001$ & $782(34.4)$ & $578(25.4)$ & $<0.001$ \\
\hline Fruit (infrequent) & $1149(66.1)$ & 1004 (57.9) & $<0.001$ & $1276(56.1)$ & $1071(47.0)$ & $<0.001$ \\
\hline Water (infrequent) & $605(34.8)$ & $515(29.7)$ & $<0.001$ & $1061(46.7)$ & $878(38.5)$ & $<0.001$ \\
\hline Regular exercise (infrequent) & $1230(70.7)$ & $1064(61.4)$ & $<0.001$ & 1765 (77.7) & $1582(69.4)$ & $<0.001$ \\
\hline Self-reported sleep quality & & & $<0.001$ & & & $<0.001$ \\
\hline Unsatisfied & $514(29.6)$ & 202 (11.6) & & $783(34.4)$ & $356(15.6)$ & \\
\hline Fair & $871(50.1)$ & 439 (25.3) & & $1068(47.0)$ & $647(28.4)$ & \\
\hline Satisfied & $354(20.4)$ & $1093(63.0)$ & & $422(18.6)$ & $1275(56.0)$ & \\
\hline Self-perceived health status & & & $<0.001$ & & & $<0.001$ \\
\hline Unsatisfied & 355 (20.4) & $97(5.6)$ & & $491(21.6)$ & $130(5.7)$ & \\
\hline Fair & 1303 (74.9) & $371(21.4)$ & & $1673(73.6)$ & $512(22.5)$ & \\
\hline Satisfied & $81(4.7)$ & $1266(73.0)$ & & $109(4.8)$ & $1636(71.8)$ & \\
\hline
\end{tabular}

*LLS: Lower life satisfaction, HLS: higher life satisfaction. 
Table 3. Factors associated with lower life satisfaction.

\begin{tabular}{|c|c|c|}
\hline Variable & aOR (95\% CI of OR) & $\mathrm{p}$ \\
\hline Age $\geq 65$ year old & $0.72(0.63-0.82)$ & $<0.001$ \\
\hline Female gender & $1.09(0.98-1.21)$ & 0.102 \\
\hline Secondary school or below & $0.95(0.86-1.06)$ & 0.374 \\
\hline Current smoker $(1$ = yes $)$ & $1.20(1.05-1.36)$ & 0.006 \\
\hline Dental check (1 = infrequent) & $1.23(1.10-1.36)$ & $<0.001$ \\
\hline Brushing teeth (1 = infrequent) & $1.12(1.02-1.23)$ & 0.022 \\
\hline Using dental floss ( 1 = infrequent) & $1.12(1.01-1.23)$ & 0.028 \\
\hline Balance diet ( 1 = infrequent $)$ & $1.64(1.45-1.84)$ & $<0.001$ \\
\hline Vegetable intake (1 = infrequent) & $1.19(1.07-1.32)$ & 0.001 \\
\hline Fruit intake ( 1 = infrequent) & $1.08(0.97-1.19)$ & 0.156 \\
\hline Water intake (1 = infrequent) & $1.14(1.03-1.25)$ & 0.009 \\
\hline Regular exercise (1 = infrequent) & $1.26(1.14-1.39)$ & $<0.001$ \\
\hline
\end{tabular}

aOR = adjusted odds ratio; $\mathrm{CI}=$ confidence interval.

\section{Discussion}

This study demonstrated that some specific behaviors were significantly associated with LLS, including cigarette smoking, an unhealthy diet, poor oral hygiene, and lack of exercise. In addition, dissatisfaction with sleep quality and health status was also associated with LLS. During this decade, many countries encountered economic depression and early retirement of civil servants. Consequently, the burden of the aging population and prevalence of chronic diseases while facing economic difficulties have increased. In the UK, Mein et al. [22] pointed out that self-perceived health status and job satisfaction were independent predictors of early retirement. Our research team [23] had previously reported that cigarette smoking was negatively associated with healthpromoting behaviors after adjustment for socioeconomic factors. Therefore, enhanced health promotion programs that can improve life satisfaction and decrease health-related problems are necessary for middle-aged people living in rural areas.

Since agriculture is the major employment in rural areas in Taiwan, most of the participants planted vegetables and fruit and sold them on the market. However, the present findings showed that many of these rural adults did not consume enough vegetables and fruit in their daily life. These results are similar to the study by Oliveira et al. [8] in Portugal. They found that insufficient fruit and vegetable intake was more frequent in younger, less educated, and less physically active subjects with a smoking habit. In a Canadian study, the higher consumption of fruit and vegetables is considered to be an indicator of healthy eating, and the protective effects for noncommunicable diseases have been investigated extensively [7]. Further study needs to explore the reasons for rural adults in failing to choose a balanced diet with sufficient fruit and vegetables.

The literature indicates that oral hygiene is essential to overall health and quality of life and plays an important role in an individual's capacity for biting, chewing, smiling, speaking, and psychosocial well-being [24]. Studies also showed that risk factors associated with tooth loss include poor oral hygiene, cigarette smoking, and unhealthy diet [25] [26]. However, many rural adults in the present study did not often brush their teeth after a meal, rarely used dental floss, and rarely received dental check. In addition, evidence emphasizes that preventing tooth loss is possible mostly through regular tooth brushing (at least twice a day), daily flossing, undergoing regular dental check-ups every 6 months, and choosing a healthy diet [5]. However, a shortage of health care providers, such as dentists and nurse practitioners, in rural and underserved areas is an issue of social and political concern in most countries. Ironically, Taiwan launched the National Health Insurance 20 years ago, and 93\% of hospitals are contracted with the program [2]. Therefore, we have no excuse to ignore the health disparities in rural areas. It is necessary to initiate related health policies that are geographically accessible to residents of the whole community through effective health promotion programs.

The present study showed that participants who adopted less frequent regular exercise reported significantly lower life satisfaction. In a physical activity and happiness study from 15 European countries, Richards et al. [27] 
found that there was a positive dose-response association between physical activity and level of happiness. Although we do not know whether the concepts of happiness and overall life satisfaction are the same, some measurement tools related to QoL include happiness items. In addition, in the Chinese and Taiwanese language or culture, life satisfaction is similar to happiness. As we know, mental health disorders are major contributors to the global burden of disease and their inverse relationship with physical activity is widely accepted [28] [29]. In Sweden, Olsson et al. [30] found a significant effect of physical activity on prescriptions during a 6-month intervention and significantly improved health-related QoL in overweight adults. Even in a study of very elderly (85-year-olds), significant associations were found between QoL and physical fitness [31]. Health promotion programs to improve life satisfaction and decreasing health-related problems are necessary for rural adults.

\section{Limitations}

The limitations of this study included the following: 1) Participants were not randomly recruited and were from the same geographic area, which limits the generalizability of the findings. 2) Self-reporting might result in underestimation of health-related behaviors, such as the amount of cigarette smoking and vegetable and water intake. 3) The descriptive study design does not allow causality to be established, and possible additional confounders might not have been measured. Further research should also consider designing a longitudinal study and including a qualitative design to explore the effects of lifestyle in greater depth.

\section{Conclusion}

Despite some limitations, this study showed that many adults did not adopt healthy habits in their life. Significant unhealthy behaviors associated with LLS were identified, including cigarette smoking, less frequent adoption of a healthy diet, oral hygiene, and exercise. The enhancement of health promotion programs to improve life satisfaction and decreasing health-related problems are necessary for rural adults.

\section{Acknowledgements}

The authors would like to thank all the residents who participated in this study for their support. We would like to acknowledge all staffs in the Chang Gung Memorial Hospital and Grant funded from the Taiwan Formosa Plastic Company (FCRPF690011) and Chang Gung Memorial Hospital (BMRP148).

\section{Competing Interests}

The authors declare that they have no competing interests.

\section{References}

[1] World Health Organization (2015) Chronic Diseases and Health Promotion. http://www.who.int/chp/about/en/

[2] Health Promotion Administration (HPA), Ministry of Health and Welfare (2015) Health Promotion Annual Report. http://www.hpa.gov.tw/English/Class.aspx?Sub=publications\&No=200705180044

[3] Chen, M.Y., Huang, W.C., Peng, Y.S., Guo, J.S., Chen, C.P., Jong, M.C. and Lin, H.C. (2011) Effectiveness of a Health Promotion Program for Farmers and Fishermen with Type 2 Diabetes in Taiwan. Journal of Advanced Nursing, 67, 2060-2067. http://dx.doi.org/10.1111/j.1365-2648.2011.05678.x

[4] Chen, C.P., Peng, Y.S., Weng, H.H., Fang, J.Y. and Chen, M.Y. (2013) Development and Preliminary Testing of a Brief Screening Measure of Healthy Lifestyle for Diabetes Patients. International Journal of Nursing Studies, 50, 9099. http://dx.doi.org/10.1016/j.ijnurstu.2012.09.001

[5] Center for Disease Control and Prevention (CDC) (2014) Preventing Cavities, Gum Disease, Tooth Loss, and Oral Cancers. http://www.cdc.gov/chronicdisease/resources/publications/AAG/doh.htm

[6] Salehi, A., Harris, N., Sebar, B. and Coyne, E. (2015) Self-Perception of Quality of Life and Its Association with Lifestyle Behaviours of Young Iranian Women. Iranian Journal of Public Health, 44, 332-340.

[7] Dehghan, M., Akhtar-Danesh, N. and Merchant, A.T. (2011) Factors Associated with Fruit and Vegetable Consumption among Adults. Journal of Human Nutrition and Dietetics, 24, 128-134. http://dx.doi.org/10.1111/j.1365-277X.2010.01142.x

[8] Oliveira, A., Maia, B. and Lopes, C. (2014) Determinants of Inadequate Fruit and Vegetable Consumption amongst Portuguese Adults. Journal of Human Nutrition and Dietetics, 2, 194-203. http://dx.doi.org/10.1111/jhn.12143 
[9] Baumann, M., Tchicaya, A., Vanderpool, K., Lorentz, N. and Le Bihan, E. (2015) Life Satisfaction, Cardiovascular Risk Factors, Unhealthy Behaviors and Socioeconomic Inequality, 5 Years after Coronary Angiography. BMC Public Health, 15, 668. http://dx.doi.org/10.1186/s12889-015-2047-0

[10] Pasareanu, A.R., Opsal, A., Vederhus, J.K., Kristensen, O. and Clausen, T. (2015) Quality of Life Improved Following In-Patient Substance Use Disorder Treatment. Health and Quality of Life Outcomes, 13, 35. http://dx.doi.org/10.1186/s12955-015-0231-7

[11] The World Health Organization Quality of Life Assessment (WHOQOL) (1995) Position Paper. Social Science \& Medicine, 41, 1403-1409.

[12] WHO (2015) WHO Quality of Life-BREF (WHOQOL-BREF). http://www.who.int/substance_abuse/research_tools/whoqolbref/en/

[13] Giuli, C., Papa, R., Bevilacqua, R., Felici, E. and Gagliardi, C. (2014) Correlates of Perceived Health Related Quality of Life in Obese, Overweight and Normal Weight Older Adults: An Observational Study. BMC Public Health, 14, 35. http://dx.doi.org/10.1186/1471-2458-14-35

[14] Ha, N.T., Duy, H.T., Le, N.H., Khanal, V. and Moorin, R. (2014) Quality of Life among People Living with Hypertension in a Rural Vietnam Community. BMC Public Health, 14, 833. http://dx.doi.org/10.1186/1471-2458-14-833

[15] Wu, M., Zhao, Q., Chen, Y., Fu, C. and Xu, B. (2015) Quality of Life and Its Association with Direct Medical Costs for COPD in Urban China. Health and Quality of Life Outcomes, 13, 57. http://dx.doi.org/10.1186/s12955-015-0241-5

[16] Hsu, W.H., Chen, C.L., Kuo, L.T., Fan, C.H., Lee, M.S. and Hsu, R.W. (2014) The Relationship between Health-Related Fitness and Quality of Life in Postmenopausal Women from Southern Taiwan. Journal of Clinical Interventions in Aging, 9, 1573-1579. http://dx.doi.org/10.2147/CIA.S66310

[17] Seib, C., Whiteside, E., Lee, K., Humphreys, J., Tran, T.H., Chopin, L. and Anderson, D. (2014) Stress, Lifestyle, and Quality of Life in Midlife and Older Australian Women: Results from the Stress and the Health of Women Study. Women's Health Issues, 24, e43-e52. http://dx.doi.org/10.1016/j.whi.2013.11.004

[18] Kuvalekar, K., Kamath, R., Ashok, L., Shetty, B., Mayya, S. and Chandrasekaran, V. (2015) Quality of Life among Persons with Physical Disability in Udupi Taluk: A Cross Sectional Study. Journal of Family Medicine and Primary Care, 4, 69-73. http://dx.doi.org/10.4103/2249-4863.152258

[19] Thomas, G., Saunders, C., Roland, M. and Paddison, C. (2015) Informal Carers’ Health-Related Quality of Life and Patient Experience in Primary Care: Evidence from 195,364 Carers in England Responding to a National Survey. BMC Family Practice, 16, 62. http://dx.doi.org/10.1186/s12875-015-0277-y

[20] Veauthier, C., Gaede, G., Radbruch, H., Wernecke, K.D. and Paul, F. (2015) Sleep Disorders Reduce Health-Related Quality of Life in Multiple Sclerosis. International Journal of Molecular Sciences, 16, 16514-16528. http://dx.doi.org/10.3390/ijms160716514

[21] Yao, K.P. (2000) WHOQOL-Taiwan Group: Introduction to the Development of the WHOQOL-Taiwan Version. Chinese Journal of Public Health, 19, 315-324.

[22] Mein, G., Martikainen, P., Stansfeld, S.A., Brunner, E.J., Fuhrer, R. and Marmot, M.G. (2000) Predictors of Early Retirement in British Civil Servants. Age and Ageing, 29, 529-536. http://dx.doi.org/10.1093/ageing/29.6.529

[23] Guo, S.E., Huang, T.J., Lin, M.S. and Chen, M.Y. (2013) Alcohol, Betel Nut, and Cigarette Consumption Are Negatively Associated with Health Promoting Behaviors in Taiwan: A Cross Sectional Study. BMC Public Health, 13, 257. http://dx.doi.org/10.1186/1471-2458-13-257

[24] World Health Organization (2015) Oral Health. http://www.who.int/mediacentre/factsheets/fs318/en/

[25] Huang, J.C., Peng, Y.S., Tu, L.T., Fan, J.Y., Jane, S.W., Chang, C.C. and Chen, M.Y. (2013) Factors Associated with Numbers of Remaining Teeth among Type 2 Diabetes: A Cross-Sectional Study. Journal of Clinical Nursing, 22, 1926-1932. http://dx.doi.org/10.1111/jocn.12225

[26] Morse, D.E., Avlund, K., Christensen, L.B., Fiehn, N.E., Molbo, D. and Holmstrup, P. (2014) Smoking and Drinking as Risk Indicators for Tooth Loss in Middle-Aged Danes. Journal of Aging and Health, 26, 54-71. http://dx.doi.org/10.1177/0898264313509278

[27] Richards, J., Jiang, X., Kelly, P., Chau, J., Bauman, A. and Ding, D. (2015) Don’t Worry, Be Happy: Cross-Sectional Associations between Physical Activity and Happiness in 15 European Countries. BMC Public Health, 15, 53. http://dx.doi.org/10.1186/s12889-015-1391-4

[28] Chang, C.F., Lin, M.S., Chou, L.N., Wang, J., Fan, J.Y. and Chen, M.Y. (2013) The Relationship between Health Promoting Behaviors and Geriatric Depression among Community Seniors. Journal of Nursing Research, 21, 75-82. http://dx.doi.org/10.1097/jnr.0b013e3182921fc9

[29] Wang, C., Li, H., Li, L., Xu, D., Kane, R.L. and Meng, Q. (2013) Health Literacy and Ethnic Disparities in HealthRelated Quality of Life among Rural Women: Results from a Chinese Poor Minority Area. Health and Quality of Life 
Outcomes, 11, 153. http://dx.doi.org/10.1186/1477-7525-11-153

[30] Olsson, S., Börjesson, M., Ekblom-Bak, E., Hemmingsson, E., Hellénius, M. and Kallings, L.V. (2015) Effects of the Swedish Physical Activity on Prescription Model on Health-Related Quality of Life in Overweight Older Adults: A Randomised Controlled Trial. BMC Public Health, 15, 687. http://dx.doi.org/10.1186/s12889-015-2036-3

[31] Takata, Y., Ansai, T., Soh, I., Awano, S., Yoshitake, Y. and Kimura, Y. (2010) Quality of Life and Physical Fitness in an 85-Year-Old Population. Archives of Gerontology and Geriatrics, 50, 272-276.

http://dx.doi.org/10.1016/j.archger.2009.04.005 